\title{
A preliminary mutation analysis of phenylketonuria in southwest Iran
}

\author{
N. Ajami ${ }^{1 *}$, S.R. Kazeminezhad ${ }^{1 *}$, A.M. Foroughmand ${ }^{1}$, M. Hasanpour ${ }^{1}$ \\ and M. Aminzadeh ${ }^{2}$ \\ ${ }^{1}$ Department of Genetics, Faculty of Science, Shahid Chamran University, \\ Ahvaz, Iran \\ ${ }^{2}$ Diabetes Research Center, Ahvaz Jundishapur University of Medical Sciences, \\ Ahvaz, Iran \\ *These authors contributed equally to this study. \\ Corresponding author: M. Aminzadeh \\ E-mail: aminzadeh_m@ajums.ac.ir
}

Genet. Mol. Res. 12 (4): 4958-4966 (2013)

Received February 5, 2013

Accepted July 18, 2013

Published October 24, 2013

DOI http://dx.doi.org/10.4238/2013.October.24.7

\begin{abstract}
Phenylketonuria (PKU) is a heterogeneous and autosomal recessive metabolic disorder that is mainly caused by mutations in the hepatic phenylalanine hydroxylase $(P A H)$ gene. This study was designed to identify $P A H$ mutations within exons 6,7 , and 10-12 in PKU patients from southwest Iran. Forty Iranian patients with clinical and biochemically confirmed PKU were enrolled. The exons were sequenced directly and 13 different mutations were identified including I224T, S231P, R176X, c.592_613del22, R243X, R252W, R261Q, Y356X, V388M, IVS10-11G $>$ A, IVS11+1G $>$ C, IVS11-2A $>$ G, and Q375R, which were associated with 23 genotypes. A novel sequence variant, Q375R (c.1124A > G), was detected in exon 11. In one patient, a typical genotype with more than two mutations (R243X/S231P/ $\mathrm{S} 231 \mathrm{P}$ ) was found. Seven different polymorphisms and three new variants were also detected in intron regions of $P A H$. A high mutation spectrum was predicted in the southwestern region of Iran due to its ethnic heterogeneity, especially the Khuzestan Province. The detection
\end{abstract}


of 13 different mutations, corresponding to a mutation detection rate of $53.75 \%$, confirmed this phenomenon.

Key words: Phenylketonuria; Phenylalanine hydroxylase; Sequencing; Mutation analysis; Southwest Iran

\section{INTRODUCTION}

Deficiency of the hepatic enzyme phenylalanine hydroxylase (PAH; EC 1.14.16.1) results in phenylketonuria (PKU; OMIM 261600), one of the most prevalent inborn errors of metabolism. In $98 \%$ of PKU patients, defects of the PAH enzyme are due to mutations in the $P A H$ gene on chromosome 12q23.2. In 1-2\% of PKU patients, mutations occur in the genes that encode enzymes for biosynthesis or regeneration of tetrahydrobiopterin (BH4), an obligatory cofactor required for the activity of PAH (Donlon et al., 2008). Blockages in the major pathway of phenylalanine (Phe) metabolism, which involves the irreversible hydroxylation of Phe to tyrosine, result in an increase of Phe in blood and other body fluids, and produces a spectrum of disorders including classical PKU, mild PKU, and mild hyperphenylalaninemia (HPA) (Williams et al., 2008). The worst consequence of increased serum Phe concentration is severe mental retardation that could be prevented by early diagnosis and implementation of a low-phenylalanine diet (Janzen and Nguyen, 2010).

Mutation analysis of PKU has proven to be clinically advantageous. PKU is a heterogeneous metabolic disorder at both the genetic and clinical levels. To date, more than $600 \mathrm{mu}-$ tations in $P A H$ have been identified and have been recorded in the $P A H$ and HGMD databases (www.pahdb.mcgill.ca and www.hgmd.org). The prevalence of PKU is roughly 1 in 15,000 individuals, but differs among different populations (Mitchell et al., 2011). In Iran, due to the absence of broad newborn screening programs, there is no precise data of PKU incidence; however, based on the latest report, the incidence of PKU might be approximately 1.6 in 10,000 (Habib et al., 2010).

\section{MATERIAL AND METHODS}

\section{Patients}

A total of 40 unrelated HPA patients (26 males, 14 females) from southwest Iran were enrolled in the present study. In families with more than one patient, only one member of each sib-pair was enrolled in this study. The age range of patients was 1-28 years. The initial diagnosis of HPA was based on clinical phenotype followed by quantitative analysis of serum amino acids using high-performance liquid chromatography.

The study was approved by the Ethics Committee of Ahvaz Jundishapur University of Medical Sciences. Based on pre-treatment Phe concentrations, patients were divided into three groups: classical PKU, mild PKU, and mild HPA. The serum Phe level of patients ranged from 179 to $2700 \mu \mathrm{M}$ (normal range $\approx 30-85 \mu \mathrm{M}$ ). After obtaining informed written consent from parents, blood samples of 2.5-3.0 mL were collected from each patient at the laboratory unit of Abuzar Children's Hospital, which is associated with the Jundishapur University of Medical Sciences. 


\section{Genomic DNA extraction}

Sufficient DNA was isolated from total blood using the Diatom DNA Prep 100 Kit. The extraction procedure of this kit is based on the salting-out method.

\section{Primers and polymerase chain reaction (PCR)}

Patients were screened for the presence of $P A H$ mutations within exons 6, 7, and 10-12, as well as adjacent flanking regions critical to mRNA processing. We selected these exons based on available data about mutation frequencies among regions, which were obtained from the $P A H$ database. Primer pairs for amplification of these exons were designed manually (Table 1). PCRs were performed in a 30- $\mu \mathrm{L}$ total volume containing 80-130 ng genomic DNA, 1X PCR buffer, $1.5 \mathrm{mM} \mathrm{MgCl}, 0.2 \mathrm{mM}$ dNTP, $0.2-0.6 \mu \mathrm{M}$ of each primer, and $3 \mathrm{U}$ Super Taq DNA polymerase (Gen Fanavaran, Tehran, Iran). PCRs were subjected to thermocycling as follows: initial denaturation at $94^{\circ} \mathrm{C}$ for $5 \mathrm{~min}$, followed by 30 cycles of denaturation at $94^{\circ} \mathrm{C}$ for $1 \mathrm{~min}$, annealing for $45 \mathrm{~s}$, and extension at $72^{\circ} \mathrm{C}$ for $1 \mathrm{~min}$, and a final extension at $72^{\circ} \mathrm{C}$ for $7 \mathrm{~min}$.

\begin{tabular}{|c|c|c|c|}
\hline Exon & Primer & Annealing temperature $\left({ }^{\circ} \mathrm{C}\right)$ & PCR product length (bp) \\
\hline 6 & F: 5'-GTGATGGCAGCTCACAGGTTCTGG-3' & 64 & 550 \\
\hline 7 & $\begin{array}{l}\text { F: 5'-TGCCTAGCGTCAAAGCCTATGTCC-3' } \\
\text { R: 5'-CTGTGGACCAGCCAGCAATGAACC-3' }\end{array}$ & 66 & 358 \\
\hline $10-11$ & $\begin{array}{l}\text { F: 5'-AGGTATCCCTTCATCCAGTCAAGG-3' } \\
\text { R: 5'-GATGAGTGGCACCAGTCAGGAGG-3' }\end{array}$ & 63 & 927 \\
\hline 12 & $\begin{array}{l}\text { F: 5'-CTGCTCTAGGGAGGTGTCCGTG-3' } \\
\text { R: 5'-GAGGTGGAGTGGAATCTAGGAAGG-3' }\end{array}$ & 64 & 459 \\
\hline
\end{tabular}

\section{DNA sequencing}

The PCR products were purified, and automated DNA sequencing was carried out in the Applied Biosystems 3730 DNA Analyzer (Macrogen, Seoul, Korea). Sequence analyses were performed using Chromas and mutation surveyor softwares. The National Center for Biotechnology Information (NCBI) BLAST tool was also used for sequence alignment.

\section{RESULTS}

\section{Phenotypic classification of patients}

Among the 40 patients, 18 were classified as classical PKU, 14 were classified as mild PKU, and five were classified as mild HPA. The pre-treatment Phe levels of three patients were not available.

\section{$P A H$ mutations and polymorphisms}

Direct sequencing of five exons and the related exon-intron boundaries of $P A H$ in 40 patients enabled the characterization of $53.75 \%$ of the studied alleles. A total of 13 different mutations were identified, including six missense mutations, three nonsense mutations, three splice site mutations, and one deletion (Table 2). In one patient, we detected a typical genotype 
with more than two mutations (R243X/S231P/S231P). The splice site mutation IVS10-11G $>$ A had the highest relative frequency at 10\%. Ten mutations, I224T, R176X, c.592_613del22, R243X, R252W, R261Q, IVS11+1G $>$ C, IVS11-2A $>$ G, V388M, and Q375R, accounted for $48.86 \%$ of mutant alleles, and three mutations, IVS10-11G $>$ A, Y356X, and S231P, accounted for $51.16 \%$ of mutant alleles. These results demonstrate the high heterogeneity of PKU in this population. Three silent mutations, Q232Q, V245V, and L385L, were detected with high frequency in exons 6,7 , and 11 , respectively. We also detected seven polymorphisms, of which three were exonic silent mutations with relatively high frequency (Table 3).

\begin{tabular}{|c|c|c|c|c|c|}
\hline \multicolumn{2}{|c|}{ Mutation } & \multirow[t]{2}{*}{ Location } & \multirow[t]{2}{*}{ Mutation type } & \multirow[t]{2}{*}{ Number of alleles } & \multirow[t]{2}{*}{ Relative frequency (\%) } \\
\hline DNA level & Protein level & & & & \\
\hline c. $1066-11 \mathrm{G}>\mathrm{A}$ & IVS10-11G $>A$ & Intron 10 & Splice & 8 & 10.0 \\
\hline c. $1068 \mathrm{C}>\mathrm{A}$ & Y356X & Exon 11 & Nonsense & 7 & 8.75 \\
\hline c. $691 \mathrm{~T}>\mathrm{C}$ & S231P & Exon 6 & Missense & 7 & 8.75 \\
\hline c. $727 \mathrm{C}>\mathrm{T}$ & $\mathrm{R} 243 \mathrm{X}$ & Exon 7 & Nonsense & 5 & 6.25 \\
\hline c. $526 \mathrm{C}>\mathrm{T}$ & R176X & Exon 6 & Nonsense & 2 & 2.50 \\
\hline c. $672 \mathrm{~T}>\mathrm{C}$ & $\mathrm{I} 224 \mathrm{~T}$ & Exon 6 & Missense & 2 & 2.50 \\
\hline c. $592 \_613 \mathrm{del} 22$ & p.Y198_E205>Sfs & Exon 6 & Deletion & 2 & 2.50 \\
\hline c. $754 \overline{\mathrm{C}}>\mathrm{T}$ & $\mathrm{R} 252 \mathrm{~W}^{-}$ & Exon 7 & Missense & 2 & 2.50 \\
\hline c. $782 \mathrm{G}>\mathrm{A}$ & R261Q & Exon 7 & Missense & 2 & 2.50 \\
\hline c. $1199+1 \mathrm{G}>\mathrm{C}$ & IVS $11+1 \mathrm{G}>\mathrm{C}$ & Intron 11 & Splice & 2 & 2.50 \\
\hline c. $1200-2 \mathrm{~A}>\mathrm{G}$ & IVS11-2A>G & Intron 11 & Splice & 2 & 2.50 \\
\hline c. $1124 \mathrm{~A}>\mathrm{G}$ & Q375R* & Exon 11 & Missense & 1 & 1.25 \\
\hline c. $1162 \mathrm{G}>\mathrm{A}$ & V388M & Exon 11 & Missense & 1 & 1.25 \\
\hline Total & & & & 43 & 53.75 \\
\hline
\end{tabular}

*Novel mutation.

Table 3. Polymorphisms found in the $P A H$ gene of 40 phenylketonuria patients from southwest Iran.

\begin{tabular}{llr}
\hline Polymorphism & Location & Frequency (\%) \\
\hline L385L & Exon 11 & 56.25 \\
Q232Q & Exon 6 & 36.25 \\
IVS5-54G $>$ A & Intron 5 & 32.50 \\
IVS10-236C $>$ T & Intron 10 & 23.75 \\
V245V & Exon 11 10 \\
IVS10+97G $>$ A & Intron 10 & 22.50 \\
IVS10-193G $>$ C & Intron 10 & 16.25 \\
IVS10+205A $>$ T & Intron 10 & 15.00 \\
IVS10+155T $>$ G & Intron 10 & 15.00 \\
IVS10 $+156 \mathrm{~T}>\mathrm{G}$ & Intron 10 & 13.75 \\
\hline
\end{tabular}

\section{Novel sequence variants}

In exon 11, we identified the alteration c.1124A $>\mathrm{G}(\mathrm{Q} 375 \mathrm{R})$ as a new variant (Table 2). The new variants IVS10+32(+A), IVS12+163(-C), and IVS13+30C $>$ T were detected in introns 10, 12, and 13, respectively (Table 4 ).

Table 4. New intronic variants identified in this study.
\begin{tabular}{llc} 
& \\
\hline Variant & Location & Frequency (\%) \\
\hline IVS10+32(+A) & Intron 10 & 2.50 \\
IVS12+163(-C) & Intron 12 & 1.25 \\
IVS13+30C $>$ T & Intron 13 & 1.25 \\
\hline
\end{tabular}




\section{Genotyping}

Genotyping was carried out in 23 of the 40 HPA patients: 16 were homozygous, 4 were heterozygous, and 3 were compound heterozygotes (Table 5).

\begin{tabular}{|c|c|c|c|c|}
\hline \multirow[t]{2}{*}{ Patient } & \multicolumn{2}{|c|}{ Genotype } & \multirow[t]{2}{*}{ Polymorphism } & \multirow[t]{2}{*}{ Pre-treatment Phe levels $(\mu \mathrm{M})$} \\
\hline & Allele 1 & Allele 2 & & \\
\hline 2 & IVS11+1G $>C$ & IVS11+1G $>C$ & Q232Q & 1560 \\
\hline 3 & $\mathrm{R} 252 \mathrm{~W}$ & $\mathrm{R} 252 \mathrm{~W}$ & & 1380 \\
\hline 5 & Y356X & Y356X & Q232Q & 1200 \\
\hline 8 & $\mathrm{I} 224 \mathrm{~T}$ & $\mathrm{I} 224 \mathrm{~T}$ & $\mathrm{Q} 232 \mathrm{Q}$ & 1440 \\
\hline 9 & IVS10-11G $>A$ & IVS10-11G $>A$ & $\begin{array}{l}\text { IVS10+155T }>C \\
\text { IVS10+156T }>\text { G } \\
\text { IVS10-193G }>C \\
\text { L385L }\end{array}$ & 1700 \\
\hline 11 & IVS10-11G $>A$ & - & $\begin{array}{l}\mathrm{Q} 232 \mathrm{Q} /- \\
\mathrm{V} 245 \mathrm{~V} /- \\
\text { IVS10+97G }>\mathrm{A} /- \\
\text { IVS10+155T }>\mathrm{C} /- \\
\text { IVS10+156T }>\mathrm{G} /- \\
\text { IVS10-193G }>\mathrm{C} /- \\
\text { L385L }\end{array}$ & 2700 \\
\hline 12 & R176X & R176X & IVS5-54G $>A$ & 1440 \\
\hline 13 & Y356X & Y356X & Q232Q & 1320 \\
\hline 14 & IVS11-2A>G & IVS11-2A>G & $\mathrm{Q} 232 \mathrm{Q}$ & 1620 \\
\hline 16 & IVS10-11G $>A$ & IVS $10-11 \mathrm{G}>\mathrm{A}$ & $\begin{array}{l}\text { IVS10+15T }>C \\
\text { IVS10 }+156 \mathrm{~T}>\mathrm{G} \\
\text { IVS10-193G }>\mathrm{C} \\
\text { L385 }\end{array}$ & 2034 \\
\hline 19 & R243X & $\mathrm{R} 243 \mathrm{X}$ & V245V & 1440 \\
\hline 20 & $\mathrm{R} 243 \mathrm{X} / \mathrm{S} 231 \mathrm{P}$ & S231P & $\begin{array}{l}\text { IVS5-54G }>A \\
\text { V245V/- }\end{array}$ & 2040 \\
\hline $21^{\mathrm{a}}$ & S231P & S231P & IVS5-54G $>A$ & 930 \\
\hline 27 & $\mathrm{R} 243 \mathrm{X}$ & - & $\begin{array}{l}\text { V245V } \\
\text { IVS10+32(+A) } \\
\text { IVS10+97G }>A \\
\text { IVS10+205A }>\text { T } \\
\text { L385L }\end{array}$ & 1600 \\
\hline 28 & S231P & $\mathrm{S} 231 \mathrm{P}$ & $\begin{array}{l}\text { IVS5-54G }>A \\
\text { Q232Q }\end{array}$ & Unknown \\
\hline $33^{\mathrm{a}}$ & R261Q & R261Q & & 1186 \\
\hline $34^{\mathrm{a}}$ & $\mathrm{S} 231 \mathrm{P}$ & Y356X & $\begin{array}{l}\text { IVS5-54G }>\text { A/- } \\
\text { Q232Q/- } \\
\text { IVS10-236C }>\text { T/- } \\
\text { L385L/- }\end{array}$ & 984 \\
\hline 35 & p.Y198_E205>Sfs & p.Y198_E205>Sfs & & 1990 \\
\hline $36^{\mathrm{a}}$ & $\mathrm{Q}^{2} 75 \mathrm{R}^{-}$ & & $\begin{array}{l}\text { IVS10+155T }>C /- \\
\text { IVS10 }+156 \mathrm{~T}>\mathrm{G} /- \\
\text { IVS10-193G }>\mathrm{C} /- \\
\text { L385L/- }\end{array}$ & 608 \\
\hline 37 & $\mathrm{R} 243 \mathrm{X}$ & - & $\begin{array}{l}\text { V245V } \\
\text { IVS10+97G }>A \\
\text { IVS10+205A }>\text { T } \\
\text { L385L }\end{array}$ & 1560 \\
\hline 38 & IVS10-11G $>A$ & IVS10-11G $>A$ & $\begin{array}{l}\text { IVS10+155T }>C \\
\text { IVS10 }+156 \mathrm{C}>\mathrm{G} \\
\text { IVS10-193G }>C \mathrm{C} \\
\text { L385L }\end{array}$ & 1850 \\
\hline $39^{\mathrm{a}}$ & Y356X & Y356X & & 1063 \\
\hline $40^{\mathrm{a}}$ & IVS10-11G $>A$ & V388M & $\begin{array}{l}\text { IVS10+155T }>C /- \\
\text { IVS10 + } 156 \mathrm{~T}>\mathrm{G} /- \\
\text { IVS10-193G }>C \\
\text { L385L/- } \\
\text { IVS13+30C }>\mathrm{T} /-\end{array}$ & 1087 \\
\hline
\end{tabular}

${ }^{a}$ Mild PKU patients, other patients are classical PKU; $(-)=$ another allele unknown; Phe $=$ phenylalanine. 


\section{DISCUSSION}

Early diagnosis via neonatal screening and initiation of treatment has prevented nearly all complications of PKU disease. Therefore, PKU represents the epitome of human biochemical genetics for the paradigm of a treatable genetic disorder (Scriver and Waters, 1999; Dobrowolski et al., 2009; Antshel, 2010; Harding and Blau, 2010). PAH mutation analysis has utility in evaluating the clinical phenotype of PKU, for genetic consultation of patients' families, prenatal diagnosis, carrier detection, and also in refining diagnoses and anticipating dietary requirements (Guldberg et al., 1998; Güttler and Guldberg, 2000; Dobrowolski et al., 2007, 2009). Many BH4-responsive mutations have been identified in various studies, and it has been estimated that more than $30 \%$ of all HPA patients respond to $\mathrm{BH} 4$, thus revealing that identification of $P A H$ mutations could be useful for BH4-based therapies (Zurflüh et al., 2008; Staudigl et al., 2011).

In the present study, we described the molecular basis of PKU in a population from the southwest of Iran by analyzing mutations in $P A H$, and evaluating correlations between genotype and phenotype. The lack of standardized methods for the classification of HPA phenotypes can complicate the interpretation of genotype-phenotype correlations (Daniele et al., 2009). In this study, we used pre-treatment plasma Phe levels for phenotypic classification.

Because patients enrolled in this study were of different ages at diagnosis and had different feeding habits and diets, a wide range of Phe levels was observed. Nonetheless, the vast majority of patients showed high pre-treatment Phe levels, as well as severe clinical manifestations. This finding could be due to the lack of systematic and comprehensive neonatal screening of PKU in Iran, and consequently the late diagnosis of PKU. Furthermore, insufficient knowledge of parents about the importance of dietary management programs likely contributed to these effects.

Among the 40 patients analyzed, 13 distinct mutations were found in combinations of 23 genotypes. In this study, the mutations IVS10-11G $>$ A, Y356X, and S231P were found in both classical and mild PKU cases. The patient with the homozygous R261Q mutation suffered from mild PKU. In spite of diagnosis at 5 years old, this patient did not present general consequences of late diagnosis, such as severe mental retardation, and the IQ was estimated to be 85 . The sibling of this patient showed the same condition, although he was diagnosed earlier, at 3 years old. This finding shows that PKU is a heterogeneous disorder at both the genotype and phenotype levels. In this study, the genotypes S231P/S231P, R261Q/R261Q, Y356X/ Y356X, S231P/Y356X, R243X/-, Q375R/-, and V388M/IVS10-11G $>$ A were each identified in patients with mild PKU. The remaining 15 genotypes appeared in classical PKU cases.

The splice mutation IVS10-11G $>$ A was detected with the highest frequency $(10 \%)$ in three homozygous patients and in one compound heterozygous patient along with V388M. A $\mathrm{G}$ to $\mathrm{A}$ transition at position 546 in intron 10 of the $P A H$ gene, located $11 \mathrm{bp}$ upstream from the intron 10/exon 11 boundary, caused the IVS10-11G $>$ A mutation. This mutation activates an alternative splice site and results in an in-frame insertion of nine nucleotides between exon 10 and exon 11 of the processed mRNA. Although the liver PAH protein content is normal in homozygous patients, no catalytic activity can be detected. This loss of enzymatic function is most likely caused by conformational changes due to the presence of three additional amino acids (Gly-Leu-Gln) between the normal sequences encoded by exon 10 and exon 11 (Dworniczak et al., 1991). This mutation has been identified as the most common mutation in Mediterranean populations such as Turkey (Dobrowolski et al., 2011), Italy (Daniele et al., 
2007), Spain (Desviat et al., 1999), Egypt (Effat et al., 1999), and Israel (Bercovich et al., 2008). In previous studies that have been performed in Iran, IVS10-11G $>$ A was also identified with the highest frequency (Bonyadi et al., 2010; Zare-Karizi et al., 2011).

The Y356X and S231P mutations showed similar frequencies of 8.75\%. Y356X was first reported in China (Wang et al., 1992), and is relatively common in East Asian countries including China, Japan, and Korea (Zhu, 2010; Okano et al., 2011). Based on phylogenetic studies, S231P is most similar to c.592 613del22, R261Q, and IVS10-11G $>$ A, which are all common Mediterranean mutations (Effat et al., 1999). The mutations I224T, R176X, c.592_613del22, R243X, R252W, R261Q, IVS11+1G $>$ C, and IVS11-2A $>$ G were equally frequent $(2.5 \%)$ in the present study. IVS11-2A $>\mathrm{G}$ was first identified in a Turkish population (Dobrowolski et al., 2011), and the present study represents the second report of this mutation. The two missense mutations, V388M and Q375R, were each detected in one allele. Kinetic studies of the mutant protein with the V388M mutation showed reduced affinity of the enzyme for L-Phe and tetrahydrobiopterin (Leandro et al., 2000). This mutation is relatively common in Brazil, Portugal, and Spain (Santos et al., 2006). The Q375R mutation is a new sequence variant that is reported in the present study for the first time, and was entered into the $P A H$ and HGMD databases. However, phylogenetic comparison revealed the conserved position of the 375-PAH residue (Protein knowledgebase: http://www.uniprot.org/; Table 6). Therefore, population and in vitro expression analyses are necessary to reveal the pathological effect of this mutation. These procedures should also be performed for the three new variants detected in intronic regions, because these variants might also have pathogenic effects.

Table 6. Conserved position of the 375-PAH residue.
\begin{tabular}{lccccccc}
\hline Organism/amino acid residue & 372 & 373 & 374 & 375 & 376 & 377 & 378 \\
\hline Human & $\mathrm{T}$ & $\mathrm{A}$ & $\mathrm{I}$ & $\mathrm{Q}$ & $\mathrm{N}$ & $\mathrm{Y}$ & $\mathrm{T}$ \\
Rat & $\mathrm{I}$ & $\mathrm{A}$ & $\mathrm{C}$ & $\mathrm{Q}$ & $\mathrm{E}$ & $\mathrm{Y}$ & $\mathrm{S}$ \\
Mouse & $\mathrm{T}$ & $\mathrm{A}$ & $\mathrm{C}$ & $\mathrm{Q}$ & $\mathrm{E}$ & $\mathrm{Y}$ & $\mathrm{T}$ \\
Caenorhabditis elegans & $\mathrm{C}$ & $\mathrm{C}$ & $\mathrm{V}$ & $\mathrm{T}$ & $\mathrm{K}$ & $\mathrm{Y}$ & $\mathrm{P}$ \\
Drosophyla melanogaster & $\mathrm{T}$ & $\mathrm{A}$ & $\mathrm{I}$ & $\mathrm{Q}$ & $\mathrm{N}$ & $\mathrm{Y}$ & $\mathrm{T}$ \\
\hline
\end{tabular}

$\mathrm{PAH}=$ phenylalanine hydroxylase. Obtained from Protein knowledgebase [http://www.uniprot.org/].

To date, more than 30 different mutations have been detected in patients with PKU living in Iran (Bonyadi et al., 2010; Zare-Karizi et al., 2011). This study is the first to report five other mutations, Y356X, S231P, I224T, IVS11-2A $>$ G, and V388M, in an Iranian population. Southwestern Iran, especially the Khuzestan Province, is comprised of heterogeneous ethnic groups; therefore, diversity in the mutation spectrum was expected. In summary, we sequenced five exons of the $P A H$ gene in $40 \mathrm{PKU}$-affected families in southwestern Iran, and identified 13 different mutations, including one novel variant. Although the Iran mutation profile of $P A H$ is similar to those of Mediterranean populations, there are several different characteristic features. The genotype-phenotype relationship, based on pre-treatment Phe levels, was also described. One notable feature of this population is its high rate of consanguineous marriage $(77.5 \%)$. With a mutation detection rate of $53.75 \%$, approximately $69.6 \%$ of patients were homozygous, $17.40 \%$ were heterozygous, and $13 \%$ were compound heterozygotes. The high homozygosity rate indicates a high rate of consanguinity in the studied cohort. Finally, the results of the present study could be advantageous for the diagnosis, genetic counseling, and planning of dietary-based treatment and other therapeutic strategies for PKU patients. 


\section{Conflicts of interest}

The authors declare no conflict of interest.

\section{ACKNOWLEDGMENTS}

This study was performed as a research project (\#U-89301) approved and supported by the Vice-Chancellor Research Center of the Ahvaz Jundishapur University of Medical Sciences. We express our gratitude to the patients and their families for their participation in the study. We also wish to thank the faculty and staff at Department of Genetics of the Shahid Chamran University.

\section{REFERENCES}

Antshel KM (2010). ADHD, learning, and academic performance in phenylketonuria. Mol. Genet. Metab. 99 (Suppl 1): S52-S58.

Bercovich D, Elimelech A, Yardeni T, Korem S, et al. (2008). A mutation analysis of the phenylalanine hydroxylase (PAH) gene in the Israeli population. Ann. Hum. Genet. 72: 305-309.

Bonyadi M, Omrani O, Moghanjoghi SM and Shiva S (2010). Mutations of the phenylalanine hydroxylase gene in Iranian Azeri Turkish patients with phenylketonuria. Genet. Test. Mol. Biomarkers 14: 233-235.

Daniele A, Cardillo G, Pennino C, Carbone MT, et al. (2007). Molecular epidemiology of phenylalanine hydroxylase deficiency in Southern Italy: a 96\% detection rate with ten novel mutations. Ann. Hum. Genet. 71: 185-193.

Daniele A, Scala I, Cardillo G, Pennino C, et al. (2009). Functional and structural characterization of novel mutations and genotype-phenotype correlation in 51 phenylalanine hydroxylase deficient families from Southern Italy. FEBS J. 276: 2048-2059.

Desviat LR, Perez B, Gamez A, Sanchez A, et al. (1999). Genetic and phenotypic aspects of phenylalanine hydroxylase deficiency in Spain: molecular survey by regions. Eur. J. Hum. Genet. 7: 386-392.

Dobrowolski SF, Ellingson C, Coyne T, Grey J, et al. (2007). Mutations in the phenylalanine hydroxylase gene identified in 95 patients with phenylketonuria using novel systems of mutation scanning and specific genotyping based upon thermal melt profiles. Mol. Genet. Metab. 91: 218-227.

Dobrowolski SF, Borski K, Ellingson CC, Koch R, et al. (2009). A limited spectrum of phenylalanine hydroxylase mutations is observed in phenylketonuria patients in western Poland and implications for treatment with 6R tetrahydrobiopterin. J. Hum. Genet. 54: 335-339.

Dobrowolski SF, Heintz C, Miller T, Ellingson C, et al. (2011). Molecular genetics and impact of residual in vitro phenylalanine hydroxylase activity on tetrahydrobiopterin responsiveness in Turkish PKU population. Mol. Genet. Metab. 102: 116-121.

Donlon J, Levy H and Scriver C (2008). Hyperphenylalaninemia: Phenylalanine Hydroxylase Deficiency. In: The Online Metabolic and Molecular Basis of Inherited Disease (Valle D, Beaudet AL, Vogelstein B, Kinzler KW, et al., eds., and Scriver CR, Childs B and Sly WS, eds. emeritus). McGraw-Hill, New York. Online Chapter 77 (www.ommbid.com).

Dworniczak B, Aulehla-Scholz C, Kalaydjieva L, Bartholome K, et al. (1991). Aberrant splicing of phenylalanine hydroxylase mRNA: the major cause for phenylketonuria in parts of southern Europe. Genomics 11: 242-246.

Effat L, Kuzmin A, Kasem N, Meguid NA, et al. (1999). Haplotypes and mutations of the PAH locus in Egyptian families with PKU. Eur. J. Hum. Genet. 7: 259-262.

Guldberg P, Rey F, Zschocke J, Romano V, et al. (1998). A European multicenter study of phenylalanine hydroxylase deficiency: classification of 105 mutations and a general system for genotype-based prediction of metabolic phenotype. Am. J. Hum. Genet. 63: 71-79.

Güttler F and Guldberg P (2000). Mutation analysis anticipates dietary requirements in phenylketonuria. Eur. J. Pediatr. 159 (Suppl 2): S150-S153.

Habib A, Falahzadeh MH, Kazerouni HR and Ganjkarimi AH (2010). Incidence of phenylketonuria in Southern Iran. IJMS 35: 137-139.

Harding CO and Blau N (2010). Advances and challenges in phenylketonuria. J. Inherit. Metab. Dis. 33: 645-648.

Janzen D and Nguyen M (2010). Beyond executive function: non-executive cognitive abilities in individuals with PKU. Mol. Genet. Metab. 99 (Suppl 1): S47-S51. 
Leandro P, Rivera I, Lechner MC, de Almeida IT, et al. (2000). The V388M mutation results in a kinetic variant form of phenylalanine hydroxylase. Mol. Genet. Metab. 69: 204-212.

Mitchell JJ, Trakadis YJ and Scriver CR (2011). Phenylalanine hydroxylase deficiency. Genet. Med. 13: 697-707.

Okano Y, Kudo S, Nishi Y, Sakaguchi T, et al. (2011). Molecular characterization of phenylketonuria and tetrahydrobiopterin-responsive phenylalanine hydroxylase deficiency in Japan. J. Hum. Genet. 56: 306-312.

Santos LL, Magalhaes MC, Reis AO, Starling AL, et al. (2006). Frequencies of phenylalanine hydroxylase mutations I65T, R252W, R261Q, R261X, IVS10nt11, V388M, R408W, Y414C, and IVS12nt1 in Minas Gerais, Brazil. Genet. Mol. Res. 5: 16-23.

Scriver CR and Waters PJ (1999). Monogenic traits are not simple. Lessons from phenylketonuria. Trends Genet. 15: 267-272.

Staudigl M, Gersting SW, Danecka MK, Messing DD, et al. (2011). The interplay between genotype, metabolic state and cofactor treatment governs phenylalanine hydroxylase function and drug response. Hum. Mol. Genet. 20: 2628-2641.

Wang T, Okano Y, Eisensmith RC, Lo WH, et al. (1992). Identification of three novel PKU mutations among Chinese: evidence for recombination or recurrent mutation at the PAH locus. Genomics 13: 230-231.

Williams RA, Mamotte CD and Burnett JR (2008). Phenylketonuria: an inborn error of phenylalanine metabolism. Clin. Biochem. Rev. 29: 31-41.

Zare-Karizi S, Hosseini-Mazinani SM, Khazaei-Koohpar Z, Seifati SM, et al. (2011). Mutation spectrum of phenylketonuria in Iranian population. Mol. Genet. Metab. 102: 29-32.

Zhu T, Qin S, Ye J, Qiu W, et al. (2010). Mutational spectrum of phenylketonuria in the Chinese Han population: a novel insight into the geographic distribution of the common mutations. Pediatr. Res. 67: 280-285.

Zurflüh MR, Zschocke J, Lindner M, Feillet F, et al. (2008). Molecular genetics of tetrahydrobiopterin-responsive phenylalanine hydroxylase deficiency. Hum. Mutat. 29: 167-175. 